\title{
Ethical Assessment of Post-Exposure Prophylaxis Guidelines in Sexual Assault Patients Suspected of Hepatitis B Viral Infection
}

\author{
JIMMY MOND M.D. PH.D., JEFFREY GRUENGLAS, DHSC(C), MBE, MA
}

jgruen@bu.edu

\begin{abstract}
More than 400,000 sexual assaults are reported annually in the United States in females and males above the age of 12. Victims are likely to include members of vulnerable populations such as the disabled, homeless persons, and immigrants. Victims of such assaults are at heightened risk of contracting the Hepatitis B virus (HBV) from their assailant. Unfortunately, approximately twothirds of people with chronic HBV are unaware of their own status, exposing for victims the risk viral transmission, disease-related cirrhosis, and hepatocellular carcinoma. Victims are also at increased risk for posttraumatic stress disorder (PTSD). Although immediate vaccination of the assaulted victim is recommended, protective levels of antibody are not present for fourteen days post vaccination. Complementary treatment with a Hepatitis B immune globulin (HBIG), however, may provide immediate protective serum concentrations. Prompt prophylactic therapeutic intervention may not only protect patients from risk of infection but may also prevent the effects of PTSD by providing victims with psychological and emotional benefit. Yet, existing Centers for Disease Control and Preventions (CDC) recommendations for suspected HBV infection in sexual assault patients recommend initiating immunoprophylaxis only in cases where the perpetrator's HBsAg status is known, a guideline that perpetuates inequities and injustice for those equally subject to the harms of sexual assault. This paper presents an ethical assessment of prophylactic treatment for sexual assault patients suspected of HBV exposure. In the absence of equitable guidelines, we argue for the clinician's duty to rescue sexually assaulted patients from future harm and to protect the public through mitigation of transmission using currently available and evidence-based treatment modalities. The paper concludes with an ethical foundation to advocate for modification of current guidelines in view of existing prophylactic regimens.
\end{abstract}

Keywords: Ethics, HBV, hepatitis B, post-exposure prophylaxis, sexual assault

*Address correspondence to: Jimmy Mond M.D. Ph.D. Chief Scientific Officer/Chief Medical Officer, ADMA Biologics. Jeffrey Gruenglas, DHSc(c), MBE, MA. Senior Director, Government Affairs and Health Policy, ADMA Biologics; College of Arts and Sciences, Boston University. Email: jgruen@bu.edu

+To cite this article: Mond, J., Gruenglas, J. "Ethical Assessment of Post-Exposure Prophylaxis Guidelines in Sexual Assault Patients Suspected of Hepatitis B Viral Infection". The Journal of Healthcare Ethics \& Administration Vol. 7, no. 3 (Summer 2021): 29-37, https://doi.org/10.22461/jhea.1.71631

This work is brought to you for free and open access by the Institute of Clinical Bioethics (ICB) at Saint Joseph's University, Philadelphia, PA, U.S.A. It has been accepted for inclusion in The Journal of Healthcare Ethics \& Administration by the editorial board and an authorized administrator of the JHEA. For more information, please contact support@jheaonline.org 


\section{INTRODUCTION}

In the United States, more than 400,000 cases of sexual assault in females and males above the age of 12 are reported annually. ${ }^{1}$ According to 2019 statistics, a sexual assault-defined as rape, forced intercourse, or other sexual behavior violations ${ }^{2}$--occurs once every 73 seconds in the United States. ${ }^{3}$ Data suggest that victims belong predominantly to vulnerable populations ranging from female college students, the disabled, and immigrants. More than $90 \%$ of sexual assault victims on college campuses never file a report and even fewer are reported to law enforcement agencies. Only $17 \%$ to $43 \%$ of those assaulted present for medical evaluation at medical facilities. ${ }^{4}$ Those who do present, appear in the emergency department setting, where they are subject to assessment by specialized sexual assault nurse examiners (SANEs) and clinicians specializing in emergency care. The Hepatitis B virus (HBV) is transmittable at a high rate, placing sexually assaulted individuals at grave risk for contracting the virus. ${ }^{5}$ Economically, the medical costs and hospitalization for patients with HBV outweigh those with human immunodeficiency virus (HIV) across acute and chronic disease settings. ${ }^{6}$

Current CDC guidelines provide for therapeutic intervention in patients suspected with HBV exposure, but this reveals a loophole in that only victims for whom the alleged assailant is known are protected, leaving those without knowledge of perpetrator HBV status unfairly discriminated and marginalized. This demarcation is unique to HBV in contrast to HIV guidelines that at minimum advocate for physician discretion of prophylactic treatment on a case by case basis even with the perpetrator HIV status unknown. Post-HBV exposure has an incubation period ranging from 60 to 180 days, with a mean of 75 days. Although screening for viral presence may be performed through a standardized virology panel, detection may not be evident for at least 4-6 weeks post exposure. During this period, suspected patients may be asymptomatic but viral penetration of hepatocytes occurs during this time.

Failure to provide patients who are suspected of exposure to HBV transmission with prophylactic measures places them at risk for viral infection upon discharge from the emergency room setting. While hepatitis vaccine is often recommended for these patients this does not provide protective levels of antibody for the 14 days ensuing vaccination during which time the virus has already gained access to the hepatocytes. Providing hepatitis immune globulin (HBIG) to these patients would provide the protection they need and cover the vulnerable time during which levels of protective antibodies can be reached following vaccination.

Patients may undergo psychological evaluation and thorough physical exam in the emergency room and released back into the community and their homes, compounding the impact of trauma to themselves and those with whom they may come into contact. On a broader level, victims may unknowingly expose their partners and risk harm to those entering into new sexual relationships. Despite a comparatively low incidence as compared to many other infectious diseases, hepatitis $\mathrm{B}$ yields a greater impact beyond patients themselves. Given the magnitude of clinical and psychological outcomes with prophylactic therapy for these unfortunate victims, the benefits justify the relatively minimal cost of medical intervention with a hyperimmune globulin. This paper presents an ethical assessment of prophylactic treatment for sexual assault patients suspected of HBV exposure. We argue that clinicians in the emergency setting have a duty to both rescue sexually assaulted patients from future harm and to protect the public through mitigation of contamination and transmission using currently available modalities that have proven success.

\section{HBV RISK IN VICTIMS OF SEXUAL ASSAULT}

The national rate of acute HBV infection has incrementally increased over the past several years. Sexual contact is the most common method of HBV transmission among adults. In 2015, more than 431,000 reported sexual assaults were reported in females and

\footnotetext{
${ }^{1}$ US Department of Justice. Criminal Victimization, 2015. October 2016

${ }^{2}$ Linden JA. New Engl J Med. 2011;365(9):834-841

${ }^{3}$ RAINN. https://www.rainn.org/about-sexual-assault

${ }^{4}$ US Department of Justice NSPOW - Facts and Statistics. Accessed September 29, 2017

${ }^{5}$ Long, L., \& Butler, B. (2018a). Sexual assault. The Obstetrician \& Gynaecologist, 20(2), 87-93. https://doi.org/10.1111/tog.12474

${ }^{6}$ Data on file. Hepatitis B and HIV Medical Cost Analysis, 2018. ADMA Biologics.
} 
males greater than 12 years of age in $2015 .{ }^{7}$ Children accounted for nearly 70,000 cases. ${ }^{8}$ According to the 2015 AAU Campus Climate Survey on Sexual Assault and Sexual Misconduct, 23\% of women reported being raped or sexually assaulted through physical force, violence, or incapacitation. Victims should be suspected of exposure to blood-borne pathogens, including hepatitis B. Despite reported data, the true incidence of HBV exposure during sexual assault is unknown and may be underreported. The paucity of these data is largely attributed to the fact that viral status of perpetrators is rarely known. ${ }^{9}$

HBV has a 50 -fold greater infectivity rate as compared to HIV-1 and can be passed through the exchange of body fluids such as semen, vaginal fluids, and blood. Bleeding and trauma to tissues, as well as possible exposure at multiple sites, exacerbates the risk of blood-borne infections being transmitted after a sexual assault, significantly greater than with consensual intercourse when on site bleeding is minimal. As a public health issue, this leaves those suspected of exposure at high personal risk as well as high risk of unknowingly spreading the disease to others through various routes of transmission. HBV infection that remains untreated with prophylactic intervention may place patients at risk for developing chronic hepatitis B-related cirrhosis and even die from hepatocellular carcinoma. Data from the Hepatitis B Foundation reports an annual incidence of nearly 30,000 in the United States, ${ }^{10}$ with the greatest incidence among those between 30 and 39 years of age, and the lowest rate among those between 0 and 19 years of age.

The clinical implications and consequences of sexual assault are well established. Once an individual is exposed to HBV and remains unprotected, the virus may take hold and develop into potentially fatal chronic liver disease. Approximately $15 \%$ to $25 \%$ of those presenting with chronic infection develop cirrhotic liver disease, which is a precursor to liver failure or hepatocellular carcinoma. Compounding the risk, fewer than $10 \%$ of patients with acute or chronic HBV who require treatment receive it. Those who go untreated may experience a litany of medical problems, including chronic pelvic pain, premenstrual syndrome, gastrointestinal disorders, gynecological symptoms, migraines and frequent headaches. ${ }^{11}$

Women who experience sexual assault have been linked to long-term effects on mental health and quality of life. Nearly $20 \%$ who had been sexually assaulted suffer from a mental health condition. ${ }^{12}$ Rape victims with underlying mental health conditions, learning disabilities, and cognitive deficits are more likely to suffer from lack of support system and are more susceptible to downstream health consequences if left untreated. Studies point to increased risk of depression, anxiety, post-traumatic stress disorder, drug and substance misuse, self-harm, and suicide. The National Center for PTSD reports that women who experience sexual assault are at increased risk for posttraumatic stress disorder (PTSD), with reports of lingering symptoms nine months after the incident. ${ }^{13}$ From a social perspective, the effects of sexual assault have been shown to devastate family dynamics as well as personal and professional relationships, can lead to significant work disability and poor productivity, and may create harmful and long-lasting consequences within the individual's community.

\section{LIMITATIONS OF CURRENT CDC GUIDELINES FOR SUSPECTED HBV EXPOSURE}

CDC guidelines for proactively managing the risk of HBV infection in victims of sexual assault lack the consistent and fair distribution of intervention across populations afforded to the HIV population (Table 1). In cases of known status of the perpetrator, guidelines for suspected HBV infection in sexual assault patients recommend, where indicated, that immunoprophylaxis with hepatitis immune globulin be initiated as soon as possible, preferably within 24 hours. It is alarming to note that in cases where the perpetrator's HBsAg status is unknown, guidelines recommend vaccination but no immediate intervention with immunoprophylaxis. ${ }^{14}$ In contrast, decision-making for patients with HIV status is afforded on a case-by-case basis and at the discretion of the physician, driven by

\footnotetext{
${ }^{7}$ The US Department of Justice. Criminal Victimization, 2015. October 2016

${ }^{8}$ The US Department of Justice NSPOW - Facts and Statistics. Accessed September 29, 2017

${ }^{9}$ CDC. USHHS. Updated Guidelines for Antiretroviral Postexposure Prophylaxis After Sexual, Injection Drug Use, or Other Nonoccupational Exposure to HIV-United States, 2016)

${ }^{10}$ Hepatitis B Foundation. https://www.hepb.org/what-is-hepatitis-b/what-is-hepb/facts-and-figures/

${ }^{11}$ Long, L., \& Butler, B. (2018a). Sexual assault. The Obstetrician \& Gynaecologist, 20(2), 87-93. https://doi.org/10.1111/tog.12474

12 Long, L., \& Butler, B. (2018a). Sexual assault. The Obstetrician \& Gynaecologist, 20(2), 87-93. https://doi.org/10.1111/tog.12474

${ }^{13}$ Department of Veterans Affairs. https://www.ptsd.va.gov/understand/types/sexual_trauma_female.asp

Viral Hepatitis-2015 STD Treatment Guidelines. (2015). Viral Hepatitis, 17.

${ }^{14}$ CDC. Postexposure Prophylaxis to Prevent Hepatitis B Virus Infection. MMWR. 55(RR16);30-31.

https://www.cdc.gov/mmwr/preview/mmwrhtml/rr5516a3.htm
} 


\section{THE JOURNAL OF HEALTHCARE ETHICS \& ADMINISTRATION}

Vol. 7 | No. 3 (Summer 2021)

clinical evidence. This gap and discrepancy in providing a therapeutic option places patients suspected of HBV exposure at unnecessary risk before they are discharged from the ER and into the community.

\begin{tabular}{|c|c|c|}
\hline \multirow[b]{2}{*}{ Source of exposure } & \multicolumn{2}{|c|}{ Treatment } \\
\hline & $\begin{array}{l}\text { Unvaccinated } \\
\text { person }^{5}\end{array}$ & $\begin{array}{l}\text { Previously } \\
\text { vaccinated } \\
\text { person }^{\mathbb{1}}\end{array}$ \\
\hline \multicolumn{3}{|l|}{ HBsAg-positive source } \\
\hline $\begin{array}{l}\text { Percutaneous (e.g., bite or needlestick) or mucosal exposure } \\
\text { to HBsAg-positive blood or body fluids }\end{array}$ & $\begin{array}{l}\text { Administer } \\
\text { hepatitis B } \\
\text { vaccine series and } \\
\text { HBIG }\end{array}$ & $\begin{array}{l}\text { Administer } \\
\text { hepatitis B } \\
\text { vaccine booster } \\
\text { dose }\end{array}$ \\
\hline Sex or needle-sharing contact of an $\mathrm{HBsAg}$-positive person & $\begin{array}{l}\text { Administer } \\
\text { hepatitis B } \\
\text { vaccine series and } \\
\text { HBIG }\end{array}$ & $\begin{array}{l}\text { Administer } \\
\text { hepatitis B } \\
\text { vaccine booster } \\
\text { dose }\end{array}$ \\
\hline $\begin{array}{l}\text { Victim of sexual assault/abuse by a perpetrator who is } \mathrm{HBsAg} \\
\text { positive }\end{array}$ & $\begin{array}{l}\text { Administer } \\
\text { hepatitis B } \\
\text { vaccine series and } \\
\text { HBIG }\end{array}$ & $\begin{array}{l}\text { Administer } \\
\text { hepatitis B } \\
\text { vaccine booster } \\
\text { dose }\end{array}$ \\
\hline \multicolumn{3}{|l|}{ Source with unknown HBsAg status } \\
\hline $\begin{array}{l}\text { Victim of sexual assault/abuse by a perpetrator with unknown } \\
\text { HBsAg status }\end{array}$ & $\begin{array}{l}\text { Administer } \\
\text { hepatitis B } \\
\text { vaccine series }\end{array}$ & No treatment \\
\hline $\begin{array}{l}\text { Percutaneous (e.g., bite or needlestick) or mucosal exposure } \\
\text { to potentially infectious blood or body fluids from a source } \\
\text { with unknown HBsAg status }\end{array}$ & $\begin{array}{l}\text { Administer } \\
\text { hepatitis B } \\
\text { vaccine series }\end{array}$ & No treatment \\
\hline $\begin{array}{l}\text { Sex or needle-sharing contact of person with unknown HBsAg } \\
\text { status }\end{array}$ & $\begin{array}{l}\text { Administer } \\
\text { hepatitis B } \\
\text { vaccine series }\end{array}$ & No treatment \\
\hline
\end{tabular}

Source: CDC. Postexposure prophylaxis to prevent hepatitis B virus infection. MMWR Recomm Rep 2006;55(No. RR-16).

Table 1. Guidelines for postexposure prophylaxis of persons with nonoccupational exposure to blood or body fluids that contain blood by exposure type and vaccination status 
The therapeutic role and clinical utility of Hepatitis B immune globulin (HBIG) in patients with HBV has been well documented in patients with acute exposure. CDC guidelines note that use of HBIG can contribute to protection until seroprotection from vaccination is achieved. ${ }^{1516}$ In patients who do not respond to a vaccine, HBIG administered offers passive immunity and protection for a period of 3 to 6 months. Passively acquired anti-HBs can be detected for 4-6 months after administration of HBIG. ${ }^{17}$

Use of vaccine is recommended in victims with no history of prior vaccination. Yet, this approach is both impractical and ineffective for a traumatized victim of assault. Any sexual assault victim is unlikely to choose an emergency room of their choice, where their personal health records may be readily accessed. Furthermore, given their current mental and psychological state, victims will rarely be able to recall their vaccination history. Attempts to uncover this information during a patient assess ment poses an unfair amount of stress and mental burden for the victim, only amplifying and exacerbating their trauma. Further, vaccines for Hepatitis B have been correlated with delayed or low levels of response particularly since a single vaccination provides minimal protection, thus falling short of providing the intended benefit of protection. Vaccine series for HBV has been correlated with delayed and low levels of response, where approximately $8 \%$ to $16 \%$ of adults fail to produce an adequate response (anti-HBs $<10$ $\mathrm{mIU} / \mathrm{mL}$ ). In fact, $42 \%$ of high-risk adults between 19 and 49 years of age and $33 \%$ of age-matched individuals not at high risk failed to demonstrate adequate vaccination coverage. In addition, responders to vaccine require at least two vaccinations to achieve protective levels; this would be unlikely to occur in these victims. Despite the availability of vaccination, coverage among most highrisk adults over 30 years of age has remained low. Risk factors for inadequate response vary in adults. These include smoking, obesity, aging, male sex, immune suppression, and chronic medical conditions. Effective vaccination requires an additional burden for adults to complete a series of schedules. Studies indicate that only $55 \%$ to $65 \%$ of those who receive their initial injection of the series complete the full vaccine series. ${ }^{18}$ Minorities and others of vulnerable populations and ethnic groups are not likely to have adequate health coverage, further increasing their risk of poor adherence to series completion. Even completion of a full series poses challenges, as demonstrated by declines in anti-HBs levels over time. In one cohort-based study, fewer than half of those vaccinated as children had detectable anti-HBs levels or antibodies 15 years post-vaccination. The CDC recommendation of vaccinating assaulted victims without the recommendation of hepatitis Ig is shortsighted and overlooks the threat of infection of HBV compared to HIV recommendations, considering that by the time an antibody response is stimulated, the virus has penetrated the hepatocyte and thus replicates. This combination of vaccine and antibodies has been shown to offer full protection in many viral infectious diseases as for example rabies and tetanus and simultaneous administration does of antigen and antibody does not lead to antibody mediated suppression.

\section{ETHICAL DUTY TO PREVENT HARM IN VULNERABLE PATIENTS}

Victims of sexual assault fall within a broader category of vulnerable or high-risk populations. This definition is broadly consistent with the CDC's characterization of other high-risk individuals, including men who have sex with men (MSM), those taking illicit drugs or trading sex for money or drugs, and people who are HIV-1 positive and at high risk for HIV or AIDS during the prior five years. These clinical parameters help to define and characterize populations particularly deserving of protection given their limitations with voluntariness, autonomy, and shared decision-making in treatment. Victims of sexual assault may be further vulnerable with compounding characteristics (Table 2).

\footnotetext{
${ }^{15}$ Schillie S, Vellozzi C, Reingold A, et al. Prevention of Hepatitis B Virus Infection in the United States: Recommendations of the Advisory Committee on Immunization Practices. MMWR Recomm Rep 2018;67(No. RR-1):1-31. DOI: http://dx.doi.org/10.15585/mmwr.rr6701a1

${ }^{16}$ Chang MH, Chen DS. Prevention of hepatitis B. Cold Spring Harb Perspect Med. 2015;5(3):a021493. Published 2015 Mar 2. doi:10.1101/cshperspect.a021493

${ }^{17}$ Schillie S, Murphy TV, Sawyer M, et al. CDC guidance for evaluating health-care personnel for hepatitis B virus protection and for administering postexposure management. MMWR Recomm Rep 2013;62(No. RR-10):1-19.

${ }^{18}$ Vaccine Safety Datalink Study
} 


\begin{tabular}{|c|c|}
\hline Female college students & $\begin{array}{l}22 \% \text { of college women encounter a forced sexual assault by their second year of } \\
\text { college, based on results of a longitudinal study of } 483 \text { women at a } \\
\text { northeastern US college. Those in their freshman year are especially vulnerable }\end{array}$ \\
\hline People with disabilities & $\begin{array}{l}\text { Presence of disability in both sexes associated with increased risk of sexual } \\
\text { coercion. }{ }^{19} 39 \% \text { of surveyed women who experienced sexual assault in the } \\
\text { preceding } 12 \text { months had a disability }\end{array}$ \\
\hline Immigrants & $\begin{array}{l}\text { Migrant women face a special risk of sexual assault. There has been a dramatic } \\
\text { decrease in immigrant reporting of sexual assault to law enforcement since } \\
\text { recent changes in US immigration policy. }\end{array}$ \\
\hline Transgendered & Nearly $50 \%$ are sexually abused or assaulted at some point in their lives \\
\hline
\end{tabular}

Table 2. Characteristics of at-risk populations of suspected HBV infection from sexual assault

These groups comprise subsets of individuals who are afforded even less protection and means of advocacy compared to the general population. Principles that guide the clinician's duty to prevent unnecessary harm are predicated on a normative foundation that recognizes limited rights and decision-making capacity of such populations. ${ }^{20}$ Two principles that specifically guide therapeutic intervention for victims of sexual assault suspected of HBV exposure-regardless of known status of the perpetratorare duty to rescue the victim and duty to protect the victim's community.

The first principle-duty to rescue-is defined as preventing serious harm to another at minimal cost to self. This obligation implies a level of duty greater than ordinary sacrifice by the layperson. ${ }^{21}$ This duty is far greater for clinicians, responders, and other professionals who are trained within scope of practice with the requisite knowledge and tools to engage in high-risk situations whose severity and likelihood of harm can be minimized. One's duty to rescue need not present significant risks, costs, or burden to the agent to be enacted. In patient's suspected of HBV exposure, the risk to the clinician is low, whereas the risk level for the patient is comparably high. These may include populations who are young, poor, living in social housing, suffering from poor health, and lack of familial support systems. In ER settings, clinicians are obligated to take on a greater than minimal duty to rescue through a duty to warn. The ER clinician who suspects a patient is at risk for infection is thus obligated to warn the patient of health risks and the consequences of both intervention and lack thereof due to gaps in the current guidelines. Failure for the clinician to intervene with prophylactic measures through HBIG intervention to protect against HBV infection is tantamount to breach of duty to warn the patient and subsequently a violation of the clinician's duty to rescue from harm. Moreover, failure to provide the patient with options for evidence-based interventions strips the patient of autonomy the make an informed decision about their health. Prophylactic strategies for intervention provide clinicians a tool by which to effectively rescue patients from the risk of infection and sequelae of organ damage and disease associated with hepatitis B. The duty to rescue is inherent to the nature of the ER setting with minimal risk to agents who act as rescuers. ${ }^{22}$ Administration of hyperimmune immune globulin to these patients may provide immediate protection with minimal financial burden to the medical community.

\footnotetext{
${ }^{19} 2010$ National Intimate Partner and Sexual Violence Survey

${ }^{20}$ Fisher, C. B. (2004). Ethics in Drug Abuse and Related HIV Risk Research. Applied Developmental Science, 8(2), 91-103. https://doi.org/10.1207/s1532480xads0802_3

${ }^{21}$ Rulli, T., \& Millum, J. (2016). Rescuing the duty to rescue. Journal of Medical Ethics, 42(4), 260-264. https://doi.org/10.1136/medethics-2013101643

${ }^{22}$ Douglas, T. (2016). Duties to rescue: Individual, professional and institutional. Journal of Medical Ethics, 42(4), $207-208$.

https://doi.org/10.1136/medethics-2016-103526
} 
The second principle-duty to protect-is predicated on the dual obligation for the clinician to promote the welfare of patient and society. ${ }^{23}$ This public health mandate is generally accepted with immunizations in practice. Beyond the clinical value of providing their patients with active immunity to potentially harmful pathogens, physicians apply evidence-based medicine of community vaccination to extend protective measures to the larger community. In a recent paper, the American College of Physicians and the CDC jointly established best practices to advance effective intervention to mitigate the spread to HBV infection to the public. ${ }^{24}$ The public's trust in the medical profession is rooted in a belief that clinicians serve the greater good of society. This premise is supported by a duty to warn others, a social responsibility to those who may be turn victim to the actions of neglect thereof by a treating physician. In Tarasoff $v$. Regents of University of California (1976), the Supreme Court of California ruled that mental health professionals have a duty to protect an intended victim of their patient's threat to harm. The law provides for the clinician to intervene by notifying law enforcement and similar means when a credible threat is determined. ${ }^{25}$ Patients suspected of HBV infection who are subsequently discharged without protective measures remain infective and carry the risk of transmission to others via various route of sexual and non-sexual exposure. The same physician under whose care is the patient bears a dual responsibility to prevent that risk from harming others.

\section{MODIFICATION TO GUIDELINES FOR HBV POST-EXPOSURE PROPHYLAXIS}

Shortcomings with formal guidelines for prophylactic intervention of sexual assault patients suspected of HBV exposure reveals a grave clinical and ethical need to address the risk of infection and transmission. To address this challenge, we call on the CDC to review current limitations of guidelines for post-exposure prophylaxis and modify their inclusion of vulnerable populations, regardless of low or no likelihood of perpetrator hepatitis B status. At minimum, adapting the current HIV post-exposure prophylaxis (PEP) guidelines-where decisions for unknown assailants are made on a "case-by-case determination" - can help to inform modification of HBV PEP guidance for sexual assault survivors. For patients at greater risk of infection, including those with unknown assailant $\mathrm{Hb}$-antigen status, prompt prophylactic therapeutic intervention with HBIG may not only protect them from risk of infection but may also prevent the effects of PTSD by providing them with psychological and emotional reassurance that all the available medical interventions are being utilized for their short- and long-term care. With a duration of 4-weeks, PEP with HBIG offers a shorter, more immediate, and cost-effective course of intervention compared to vaccination alone, resulting in effective protection if administered within 14 days of exposure. ${ }^{26}$ Although we found in the literature no cost-benefit analysis comparing HBIG with HBV vaccines, several studies with Asian neonates have demonstrated the cost-effectiveness of implementing immune globulin alone or in tandem with active and passive immunization. ${ }^{2728}$ Unlike vaccination alone, intervention with HBIG provides a greater level of certainty in producing immediate and HIB levels of protective antibodies, thus providing greater re-assurance for patients and a more reliable effect of mitigating psychological trauma related to the suspected infection.

\footnotetext{
${ }^{23}$ American Medical Association. (n.d.). Code of Medical Ethics: Patient-physician relationships. https://www.ama-assn.org/deliveringcare/ethics/code-medical-ethics-patient-physician-relationships

${ }^{24}$ Abara, W. E., Qaseem, A., Schillie, S., McMahon, B. J., Harris, A. M., \& High Value Care Task Force of the American College of Physicians and the Centers for Disease Control and Prevention (2017). Hepatitis B Vaccination, Screening, and Linkage to Care: Best Practice Advice From the American College of Physicians and the Centers for Disease Control and Prevention. Annals of internal medicine, 167(11), 794-804.

https://doi.org/10.7326/M17-1106

${ }^{25}$ Tarasoff v. Regents of University of California. 17 Cal.3d 425 (1976). https://scocal.stanford.edu/opinion/tarasoff-v-regents-university-california30278

${ }^{26}$ Freeland, C., Cohen, C., \& Collier, M. G. (2018). Public Health Response to Hepatitis B Exposure: A Case Study on Gaps and Opportunities to Improve Postexposure Care. Infectious Diseases in Clinical Practice, 26(4), 185-186. https://doi.org/10.1097/IPC.0000000000000656

${ }^{27}$ Chen, S. C., Toy, M., Yeh, J. M., Wang, J. D., \& Resch, S. (2013). Cost-effectiveness of augmenting universal hepatitis B vaccination with immunoglobin treatment. Pediatrics, 131(4), e1135-e1143. https://doi.org/10.1542/peds.2012-1262

${ }^{28}$ Guo, Y., Zhang, W., Zhang, Y., Lin, X., Zhang, B., Chen, C., \& Du, Y. (2012). Cost-effectiveness analysis of preventing mother-to-child transmission of hepatitis B by injecting hepatitis B immune globulin. European journal of gastroenterology \& hepatology, 24(12), 1363-1369.

https://doi.org/10.1097/MEG.0b013e32835847c6
} 


\section{CONCLUSION}

In view of the significantly heightened infectivity of the hepatitis B virus, we argue that the medical community would benefit from greater awareness of the risk of HBV in sexual assault patients and the clinical rationale for use of additional prophylactic intervention beyond the recommendation of vaccination. In view of the fact that serum anti-Hb levels through vaccination may decline over time and in view of the fact that many individuals in the susceptible populations never complete the full series of vaccinations complementary treatment with hepatitis immune globulin B PEP intervention may provide the greatest and most immediate seroprotective properties. The duty to rescue individual sexual assault patients from further harm and the institutional duty to protect the public provides an ethical imperative to ensure such vulnerable populations are better protected from risk of infection, independent of the imposition to have knowledge of their assailant's viral status. The principle of protection against harm applies at the institutional level beyond the individual practitioner, since communities place trust in the hospital system to serve the public. Expanding the guidelines to include evidence-based PEP intervention with HBIG in any patient with unknown HBsAg status is a positive step forward in protecting these vulnerable and exposed populations, as have been done with HIV. We encourage the CDC to review current HBV PEP guidelines and modify them to ensure clinicians have appropriate guidance to address the needs of sexual assault patients.

\section{DISCLOSURE}

This work did not include human or animal research and meets HIPAA compliance. No funding was provided. The authors have no conflicts of interest to disclose.

\section{REFERENCES}

1. US Department of Justice. Criminal Victimization, 2015. October 2016

2. Linden JA. New Engl J Med. 2011;365(9):834-841

3. RAINN. https://www.rainn.org/about-sexual-assault

4. US Department of Justice NSPOW - Facts and Statistics. Accessed September 29, 2017

5. Long, L., \& Butler, B. (2018a). Sexual assault. The Obstetrician \& Gynaecologist, 20(2), 87-93. https://doi.org/10.1111/tog.12474

6. Data on file. Hepatitis B and HIV Medical Cost Analysis, 2018. ADMA Biologics.

7. The US Department of Justice. Criminal Victimization, 2015. October 2016

8. The US Department of Justice NSPOW - Facts and Statistics. Accessed September 29, 2017

9. CDC. USHHS. Updated Guidelines for Antiretroviral Postexposure Prophylaxis After Sexual, Injection Drug Use, or Other Nonoccupational Exposure to HIV-United States, 2016)

10. Hepatitis B Foundation. https://www.hepb.org/what-is-hepatitis-b/what-is-hepb/facts-and-figures/

11. Long, L., \& Butler, B. (2018a). Sexual assault. The Obstetrician \& Gynaecologist, 20(2), 87-93. https://doi.org/10.1111/tog.12474

12. Long, L., \& Butler, B. (2018a). Sexual assault. The Obstetrician \& Gynaecologist, 20(2), 87-93. https://doi.org/10.1111/tog.12474

13. Department of Veterans Affairs. https://www.ptsd.va.gov/understand/types/sexual_trauma_female.asp. Viral Hepatitis-2015 STD Treatment Guidelines. (2015). Viral Hepatitis, 17.

14. CDC. Postexposure Prophylaxis to Prevent Hepatitis B Virus Infection. MMWR. 55(RR16);30-31. https://www.cdc.gov/mmwr/preview/mmwrhtml/rr5516a3.htm

15. Schillie S, Vellozzi C, Reingold A, et al. Prevention of Hepatitis B Virus Infection in the United States: Recommendations of the Advisory Committee on Immunization Practices. MMWR Recomm Rep 2018;67(No. RR-1):1-31. DOI: http://dx.doi.org/10.15585/mmwr.rr6701a1

16. Chang MH, Chen DS. Prevention of hepatitis B. Cold Spring Harb Perspect Med. 2015;5(3):a021493. Published 2015 Mar 2. doi:10.1101/cshperspect.a021493

17. Schillie S, Murphy TV, Sawyer M, et al. CDC guidance for evaluating health-care personnel for hepatitis B virus protection and for administering postexposure management. MMWR Recomm Rep 2013;62(No. RR-10):1-19.

18. Vaccine Safety Datalink Study

19. 2010 National Intimate Partner and Sexual Violence Survey 


\section{THE JOURNAL OF HEALTHCARE ETHICS \& ADMINISTRATION}

Vol. 7 | No. 3 (Summer 2021)

20. Fisher, C. B. (2004). Ethics in Drug Abuse and Related HIV Risk Research. Applied Developmental Science, 8(2), 91-103. https://doi.org/10.1207/s1532480xads0802_3

21. Rulli, T., \& Millum, J. (2016). Rescuing the duty to rescue. Journal of Medical Ethics, 42(4), 260-264.

https://doi.org/10.1136/medethics-2013-101643

22. Douglas, T. (2016). Duties to rescue: Individual, professional and institutional. Journal of Medical Ethics, 42(4), 207-208. https://doi.org/10.1136/medethics-2016-103526

23. American Medical Association. (n.d.). Code of Medical Ethics: Patient-physician relationships. https://www.ama-assn.org/delivering-care/ethics/code-medical-ethics-patient-physician-relationships

24. Abara, W. E., Qaseem, A., Schillie, S., McMahon, B. J., Harris, A. M., \& High Value Care Task Force of the American College of Physicians and the Centers for Disease Control and Prevention (2017). Hepatitis B Vaccination, Screening, and Linkage to Care: Best Practice Advice From the American College of Physicians and the Centers for Disease Control and Prevention. Annals of internal medicine, 167(11), 794-804. https://doi.org/10.7326/M17-1106

25. Tarasoff v. Regents of University of California. 17 Cal.3d 425 (1976). https://scocal.stanford.edu/opinion/tarasoff-v-regents-university-california-30278

26. Freeland, C., Cohen, C., \& Collier, M. G. (2018). Public Health Response to Hepatitis B Exposure: A Case Study on Gaps and Opportunities to Improve Postexposure Care. Infectious Diseases in Clinical Practice, 26(4), 185186. https://doi.org/10.1097/IPC.0000000000000656

27. Chen, S. C., Toy, M., Yeh, J. M., Wang, J. D., \& Resch, S. (2013). Cost-effectiveness of augmenting universal hepatitis B vaccination with immunoglobin treatment. Pediatrics, 131(4), e1135-e1143. https://doi.org/10.1542/peds.2012-1262

28. Guo, Y., Zhang, W., Zhang, Y., Lin, X., Zhang, B., Chen, C., \& Du, Y. (2012). Cost-effectiveness analysis of preventing mother-to-child transmission of hepatitis $B$ by injecting hepatitis $B$ immune globulin. European journal of gastroenterology \& hepatology, 24(12), 1363-1369. https://doi.org/10.1097/MEG.0b013e32835847c6 